\title{
Development and evaluation of a monoclonal antibody-based competitive ELISA for the detection of antibodies against $\mathrm{H7}$ avian influenza virus
}

\author{
Yuan Li ${ }^{1}$, Hongliu Ye ${ }^{1}$, Meng Liu', Suquan Song ${ }^{1}$, Jin Chen ${ }^{2}$, Wangkun Cheng ${ }^{3}$ and Liping Yan ${ }^{1^{*}}$ (D)
}

\begin{abstract}
Background: $\mathrm{H} 7$ subtype avian influenza has caused great concern in the global poultry industry and public health. The conventional serological subtype-specific diagnostics is implemented by hemagglutination inhibition (HI) assay despite lengthy operation time. In this study, an efficient, rapid and high-throughput competitive enzyme-linked immunosorbent assay (CELISA) was developed for detection of antibodies against $\mathrm{H} 7$ avian influenza virus (AIV) based on a novel monoclonal antibody specific to the hemagglutinin (HA) protein of H7 AlV.

Results: The reaction parameters including antigen coating concentration, monoclonal antibody concentration and serum dilution ratio were optimized for $\mathrm{H} 7$ antibody detection. The specificity of the cELISA was tested using antisera against $\mathrm{H} 1 \sim \mathrm{H} 9, \mathrm{H} 11 \sim \mathrm{H} 14$ Alvs and other avian viruses. The selected cut-off values of inhibition rates for chicken, duck and peacock sera were $30.11,26.85$ and $45.66 \%$ by receiver-operating characteristic (ROC) curve analysis, respectively. With $\mathrm{HI}$ test as the reference method, the minimum detection limits for chicken, duck and peacock positive serum reached $2^{0}, 2^{1}$ and $2^{-1} \mathrm{HI}$ titer, respectively. Compared to $\mathrm{HI}$ test, the diagnostic accuracy reached 100, 98.6, and 99.3\% for chicken, duck and peacock by testing a total of 400 clinical serum samples, respectively.

Conclusions: In summary, the cELISA assay developed in this study provided a reliable, specific, sensitive and speciesindependent serological technique for rapid detection of $\mathrm{H7}$ antibody, which was applicable for large-scale serological surveillance and vaccination efficacy evaluation programs.
\end{abstract}

Keywords: Avian influenza virus, H7 subtype, Competitive ELISA, Antibody detection

\section{Background}

Avian influenza, a highly contagious respiratory viral disease caused by the avian influenza virus (AIV), continues to impair the domestic poultry and human public health with enormous economic losses alarmingly worldwide

\footnotetext{
* Correspondence: yanliping@njau.edu.cn

${ }^{1}$ MOE Joint International Research Laboratory of Animal Health and Food Safety, Jiangsu Engineering Laboratory of Animal Immunology, Jiangsu Detection Center of Terrestrial Wildlife Disease, Institute of Immunology and College of Veterinary Medicine, Nanjing Agricultural University, Nanjing, Jiangsu 210095, People's Republic of China

Full list of author information is available at the end of the article
}

[1-3]. AIV, whose genome consists of eight negative sense single-stranded RNA segments that encode at least 11 proteins, belongs to the genus Influenza virus A of the family Orthomyxoviridae [4]. According to the antigenic divergence of hemagglutinin (HA) and neuraminidase (NA) surface glycoproteins, AIV comprises 16 HA subtypes and 9 NA subtypes. Influenza A viruses isolated from avian species fall into two pathotypes on the basis of their virulence in chickens: low pathogenicity avian influenza virus (LPAIV) and highly pathogenic avian influenza virus (HPAIV). Among the 16 HA subtypes of

C C The Author(s). 2021 Open Access This article is licensed under a Creative Commons Attribution 4.0 International License, which permits use, sharing, adaptation, distribution and reproduction in any medium or format, as long as you give appropriate credit to the original author(s) and the source, provide a link to the Creative Commons licence, and indicate if changes were made. The images or other third party material in this article are included in the article's Creative Commons licence, unless indicated otherwise in a credit line to the material. If material is not included in the article's Creative Commons licence and your intended use is not permitted by statutory regulation or exceeds the permitted use, you will need to obtain permission directly from the copyright holder. To view a copy of this licence, visit http://creativecommons.org/licenses/by/4.0/ The Creative Commons Public Domain Dedication waiver (http://creativecommons.org/publicdomain/zero/1.0/) applies to the data made available in this article, unless otherwise stated in a credit line to the data. 
AIV, H7 subtype is one of two HA subtypes capable of mutating into HPAIV after transmission to domestic poultry [5]. The HA surface glycoproteins of HPAIV possess multiple basic amino acids at the cleavage site identified by ubiquitous proteases present in a wide range of host cells, allowing for lethal systemic infection in poultry [6].

Phylogenetically, H7 AIV with HA gene compatible with all nine NA subtype genes (N1-N9) is divided into two distinct genetic lineages, North American or Eurasian [7]. So far, infections with H7 AIV have been documented in wild birds, domestic poultry and mammals including humans. Over the past few decades, ongoing outbreaks in poultry caused by HPAIV and LPAIV of the H7N1, H7N2, H7N3, H7N4, H7N6, H7N7 and H7N9 subtypes in both lineages have led to millions of birds' depopulation [7]. Remarkably, the diversity in geographic distribution of countries affected by the $\mathrm{H} 7$ subtype in poultry solidly manifests the global threats towards poultry industry posed by H7 AIV $[8,9]$. More seriously, viruses within both American and Eurasian lineages including $\mathrm{H} 7 \mathrm{~N} 2$, H7N3, H7N7 and H7N9 have turned out to cross the species barrier to cause human infection [10]. The most recent five waves of H7N9 epidemic in China since 2013 further prompt global concerns about an increasing $\mathrm{H} 7$ pandemic potential [11]. Therefore, constant vigilance and continuous intensive surveillance are required to minimize the risk of domestic poultry and human infection with the H7 AIV.

As the prerequisite for epidemiologic surveillance studies as well as evaluation of vaccine immunogenicity, serological investigations to detect specific $\mathrm{H} 7$ antibodies in poultry are of instructive importance. Classical laboratory serologic tools used for measuring anti-AIV antibodies are agar gel immunodiffusion (AGID), hemagglutination inhibition (HI) test and virus neutralization (VN) test. The AGID test is a simple and economical assay for detection of antibodies to influenza A virus group-specific antigens, namely the ribonucleoprotein and matrix proteins; however, it is also time consuming and not suitable for large-scale clinical specimens screening [12]. HI assay remains the official subtype-specific test for influenza serologic differential diagnosis, but the downsides of this approach include the needs for antigen titration, red blood cells standardization, nonspecific inhibitors removal and long processing time for test results [13]. The VN test is recommended for the identification of HPAIV with limited values in rapid and highthroughput diagnostics for the use of live infectious viruses [13]. In comparison to the aforementioned serologic methods, enzyme-linked immunosorbent assay (ELISA) technique is widely accepted as an essential methodology superior in throughput, speed and accuracy for early diagnosis [14]. Among different types of ELISA tests, indirect ELISA is considered as a valuable and inexpensive test routinely used for the detection of antibodies to AIV in birds. However, this technique is not feasible when screening samples from a wide range of bird species. As an alternative, competitive ELISA (cELISA) format, also called epitope-blocking ELISA can achieve this purpose with no need of species-specific enzyme-conjugated antibodies [15].

To successfully construct a qualified cELISA immunoassay, a highly specific monoclonal antibody $(\mathrm{mAb})$ is necessary to recognize a broadly conserved and dominant antigenic epitope throughout $\mathrm{H} 7$ strains which can consistently induce antibody response in infected or vaccinated hosts. Notably, HA1 subunit of HA molecule, as the major surface glycoprotein, contains the immunodominant antigenic sites to elicit virus-neutralizing antibodies in birds, rendering it a vital target for $\mathrm{mAb}$ production [16]. Yao $\mathrm{Lu}$ et al. successfully generated high-affinity mAbs directed against a dominant conserved epitope of recombinant H7-HA1 protein as described previously [17]. In this study, a cELISA immunoassay based on mAb 2F8 to measure serum antibody responses against $\mathrm{H} 7$ strains from different susceptible avian species was developed with high specificity, sensitivity and low variability.

\section{Methods}

\section{Viruses, cells, and animals}

The H7 AIV used in the study was a low-pathogenic strain constructed with the internal gene fragments of A/Puerto Rico/8/34 (H1N1) as the backbone through reverse genetics. $\mathrm{H} 7$ positive hybridoma cell line $2 \mathrm{~F} 8$ was cultured in RPMI-1640 medium supplemented with $10 \%$ foetal calf serum (Gibco-BRL, USA) at $37^{\circ} \mathrm{C}$ with $5 \%$ $\mathrm{CO}_{2}$. A total of nine six-week-old female $\mathrm{BALB} / \mathrm{c}$ mice weighing between 22 and $25 \mathrm{~g}$ were purchased from the Sino-British SIPPR/BK Lab Animal Ltd. (Shanghai, China). The mice were fed with standard commercial diet and raised in individually ventilated cages in a clean facility at our laboratory.

\section{Serum samples}

The experimental standard sera were obtained from our laboratory as described previously [18]. A total of thirtysix three-month-old specific-pathogen-free (SPF) chickens were purchased from Shennong Company in Zhejiang province of China. They were randomly divided into 18 groups and reared separately in SPF isolators to prepare experimental standard sera. The inactivated AIV (H1N1, H2N2, H3N8, H4N6, H5N1, H6N5, H7N3, H8N4, H9N2, H11N9, H12N5, H13N6 and H14N5), Newcastle disease virus (NDV), avian infectious bronchitis virus (IBV), infectious bursal disease virus (IBDV) and avian leukosis virusJ subgroup (ALV-J) were emulsified in complete Freund's adjuvant $(1,1)$ and injected subcutaneously to the SPF chickens, respectively. The above virus strains were 
preserved at $-80^{\circ} \mathrm{C}$ at the author's laboratory. Another group of two SPF chickens were injected with phosphate buffered saline (PBS) as a negative control. After 2 weeks, a second immunization was administered with the above inactivated viruses emulsified 1:1 in incomplete Freund's adjuvant. A booster was administered at a two-week interval. Standard monospecific antisera were prepared from the blood collected 10 days after the booster immunization (Table 1). Standard negative sera were harvested from SPF chickens prior to immunization. After the blood was collected from leg veins of SPF chickens, they were euthanized in $\mathrm{CO}_{2}$. These experimental sera were separated from whole blood by centrifugation at $2000 \times g$ for $10 \mathrm{~min}$ after overnight incubation at $4{ }^{\circ} \mathrm{C}$ and then stored at $-40^{\circ} \mathrm{C}$ until use. They were previously evaluated by $\mathrm{HI}$ assays or commercial ELISA kits and then subjected to the cELISA assay.

In this study, a total of 400 clinical serum samples from chicken, duck and peacock were obtained. The 260 chicken and duck clinical serum samples used in this study were collected from poultry farms of Jiangsu province in China and categorized into positive or negative sera by HI assay. The 140 peacock clinical serum samples were gathered from Nanjing Hongshan Forest Zoo, of which the 100 positive peacock clinical sera verified by $\mathrm{HI}$ assay were collected sequentially 1 month after the immunization of reassortant AIV $(\mathrm{H} 5+\mathrm{H} 7)$ trivalent vaccine, and 40 negative peacock clinical sera were collected before immunization.

\section{Identity and preparation of antigen}

Each 10-day-old SPF embryonated chicken egg was inoculated via the allantoic cavity with the H7 AIV diluted in $100 \mu \mathrm{L} 0.01 \mathrm{M}$ sterile PBS. During the incubation period at $37^{\circ} \mathrm{C}$ for $2-3$ days, eggs were monitored twice daily for embryo mortality. Embryos which died within $24 \mathrm{~h}$ were discarded. After eggs were chilled at $4{ }^{\circ} \mathrm{C}$ overnight, allantoic fluids confirmed by hemagglutination (HA) test were aseptically harvested and combined. The allantoic fluids of $\mathrm{H} 7$ viruses were further inactivated by administration of $\beta$-propiolactone diluted at a proportion of 1 : 2000 with PBS at $4{ }^{\circ} \mathrm{C}$ for $12 \mathrm{~h}$. An inactivated status was detected by antigen challenge in 10-days-old SPF eggs for 3 days to check for live viruses by $\mathrm{HA}$ test. The validated inactivated virus suspensions were further clarified by centrifugation at $12,000 \times \mathrm{g}$ at $4{ }^{\circ} \mathrm{C}$ for 10 min. Virus supernatants were collected and pelleted by ultracentrifugation at $110,000 \times \mathrm{g}$ at $4{ }^{\circ} \mathrm{C}$ for $1.5 \mathrm{~h}$ and subsequently the virus precipitates were suspended by $3-6 \mathrm{~mL}$ PBS. Thereafter, the precipitated viruses were ultracentrifuged at $160,000 \times \mathrm{g}$ at $4{ }^{\circ} \mathrm{C}$ for $3 \mathrm{~h}$ by using the sucrose gradient centrifugation to remove impurities of different densities. Finally, the purified viruses underwent ultracentrifugation at 160 , $000 \times \mathrm{g}$ at $4{ }^{\circ} \mathrm{C}$ for $2.5 \mathrm{~h}$ to remove sucrose followed by suspension with $2 \mathrm{~mL}$ PBS. The successfully purified viruses were evaluated and stored at $-80^{\circ} \mathrm{C}$. All viral manipulations were performed under appropriate biosafety level 2 laboratory conditions.

Table 1 The information profile of standard positive chicken antisera

\begin{tabular}{|c|c|c|c|}
\hline Strain name & Strain description & Highly similar sequences $^{\mathrm{a}}(\geq 99 \%)$ & HI titer $\left(2^{x}\right)$ \\
\hline AIV-H1N1 P2009 & H1N1 & MH061695.1 & 10 \\
\hline AIV-H2N2 21103 & $\mathrm{H} 2 \mathrm{~N} 2$ & L11134.1 & 10 \\
\hline AIV-H3N8 11102 & H3N8 & CY005816.1 & 8 \\
\hline AIV-H4N6 20411 & H4N6 & GU052381.1 & 7 \\
\hline AlV-H5N1 060315 & H5N1 & JX565019.1 & 9 \\
\hline AIV-H6N5 20411 & H6N5 & CY014656.1 & 9 \\
\hline AIV-H7N3 201369 & H7N3 & JQ906576.1 & 6 \\
\hline AIV-H8N4 20413 & H8N4 & CY014659.1 & 9 \\
\hline AIV-H9N2 201313 & H9N2 & KF059279.1 & 10 \\
\hline AIV-H11N9 21103 & H11N9 & CY014687.1 & 8 \\
\hline AlV-H12N5 11103 & $\mathrm{H} 12 \mathrm{~N} 5$ & GU052216.1 & 5 \\
\hline AIV-H13N6 11103 & H13N6 & CY014694.1 & 8 \\
\hline H14-A1131028 & H14N5 & KF986854.1 & 10 \\
\hline NDV (Lasota) & NDV & DQ195265.1 & 9 \\
\hline IBV-J (F8)050309 & IBV & FJ849834.1 & - \\
\hline IBDV-NB(F7) & IBDV & AY319768.2 & - \\
\hline ALV-J & ALV-J & KM655820.1 & - \\
\hline
\end{tabular}

${ }^{\mathrm{a}}$ Accession number from the GenBank databases 


\section{Preparation of anti-H7-HA1 mAb}

The mAb 2F8 directed against recombinant H7-HA1 protein was produced as described previously [17]. In brief, six-week-old female BALB/c mice were first injected at multiple sites subcutaneously with $50 \mu \mathrm{g}$ of recombinant H7-HA1 protein mixed with an equal volume of Freund's complete adjuvant, and then injected intraperitoneally with $50 \mu \mathrm{g}$ of recombinant $\mathrm{H} 7-\mathrm{HA} 1$ protein mixed with an equal volume of Freund's incomplete adjuvant for two times at 14 and 28 days after the first injection. Three days after the final injection with $100 \mu \mathrm{g}$ of the protein, spleen cells from the immunized mice were fused with myeloma cells $(\mathrm{sp} 2 / 0)$, and the positive hybridoma were screened by indirect ELISA results against recombinant $\mathrm{H} 7-\mathrm{HA} 1$ protein. The selected clones were further subcloned four times by limiting dilution to obtain stable monoclone, and confirmed by western blot assay, immunofluorescence assay, $\mathrm{HI}$ assay, blocking assay and neutralization assay.

Each mouse received an intraperitoneal inoculation of $0.5 \mathrm{~mL}$ liquid paraffin. Following 7 days, hybridoma cells were diluted in serum-free RPMI-1640 medium. The mAb 2F8 ascites were prepared by injecting intraperitoneally $5 \times$ $10^{6}$ diluted positive hybridoma cells into each paraffin- primed six-week-old BALB/c mice. Following a further 7 days, mouse ascites production was monitored daily. Ascites were considered to have generated when obvious abdominal swelling was observed and skin tension was palpable. At the end of the experiment, all the mice were euthanized via $\mathrm{CO}_{2}$ inhalation. Subsequently, the mAb 2F8 was purified from ascites via caprylic acid-ammonium sulfate precipitation followed by HiTrap Protein G affinity chromatography (Amersham, Sweden) according to the manufacturer's instructions.

\section{Establishment of the cELISA immunoassay}

The cELISA assay runs according to the workflow illustrated in Fig. 1. Each well of 96 -well microtiter plates (JET BIOFIL, China) was coated overnight at $4{ }^{\circ} \mathrm{C}$ with $100 \mu \mathrm{L}$ coating buffer $(0.05 \mathrm{M}$ carbonate/bicarbonate buffer, $\mathrm{pH}=9.6$ ) containing the purified $\mathrm{H} 7$ inactivated whole virus particles at working concentration. After five rapid washes with $300 \mu \mathrm{L}$ PBS buffer containing $0.05 \%$ Tween-20 (PBST), plates were then blocked with $300 \mu \mathrm{L}$ blocking solution (PBS buffer containing 5\% skimmed milk) at $37^{\circ} \mathrm{C}$ for $1 \mathrm{~h}$. After rinsing five times with PBST, equal volumes of unknown serum samples and

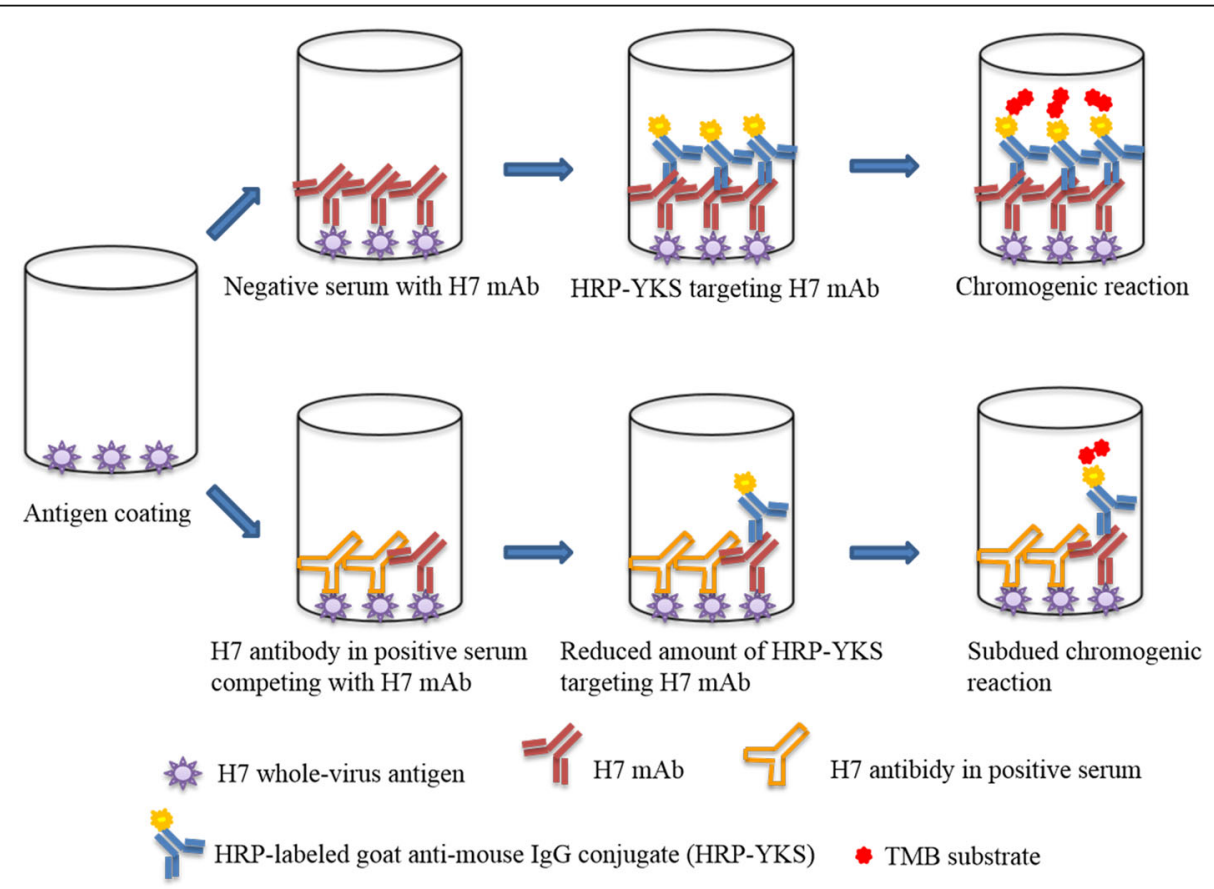

Fig. 1 Schematic illustration of the cELISA immunoassay for the detection of H7 antibody. A 96-well microtiter plate coated with purified inactivated $\mathrm{H} 7$ whole-virus antigen is prepared. The mixture of primary competitive mAb and unknown serum sample is diluted to optimal concentration and added to the antigen coated plate. After an incubation period of $1 \mathrm{~h}$, the plate is washed to remove unbound antibody and a secondary antibody labeled with horseradish peroxidase specific for targeting the competitive mAb is added. After another incubation of 30 min, the plate is washed again to remove unbound secondary antibody and then the substrate is added. If the serum sample is negative, the enzyme on secondary antibody which binds specifically the murine competitive mAb linked on the antigen-coated plate will catalyze the substrate and result in a color change. In contrast, the antibody in positive serum sample will compete with competitive mAb for capturing the same epitope of coated antigen. Subdued color change will be observed due to the species-specific property of the secondary antibody. The color intensity resulting from antigen bound $\mathrm{mAb}$ is inversely proportional to the amount of epitope-specific antibody present in test serum 
competitive mAb diluted to working concentration with blocking buffer were mixed and incubated simultaneously at $37^{\circ} \mathrm{C}$ for $1 \mathrm{~h}$. Wells added with competitive $\mathrm{mAb}$ mixed with standard monospecific antisera, negative sera or no serum served as positive, negative or blank control respectively. To provide results statistically valid, each serum sample was tested in triplicate. After washing steps for five times, $100 \mu \mathrm{L}$ horseradish peroxidase-labeled goat anti-mouse IgG conjugate diluted to an optimal dilution was placed in each well at $37^{\circ} \mathrm{C}$ for $30 \mathrm{~min}$, followed by the same washing steps as described above. After $100 \mu \mathrm{L}$ tetramethylbenzidine (TMB) substrate was added to each well followed by incubation in the dark at room temperature for $5 \mathrm{~min}$, $50 \mu \mathrm{L}$ stop solution (2 M sulfuric acid) per well was added to terminate the colorimetric reaction and optical density at $450 \mathrm{~nm}\left(\mathrm{OD}_{450}\right)$ were measured by an automated multimode reader. Results were interpreted as the percentage of inhibition (PI) calculated according to the following formula: $\%$ inhibition $=\left(\left(\mathrm{OD}_{450}\right.\right.$ of $\mathrm{mAb}-\mathrm{OD}_{450}$ of serum sample) $/ \mathrm{OD}_{450}$ of $\left.\mathrm{mAb}\right) \times 100 \%$.

To standardize the assay, the optimal concentrations of inactivated antigen and competitive $\mathrm{mAb}$ were determined by means of checkerboard titration. The coating antigen concentrations in the range of 2, 4, 6 and $8 \mu \mathrm{g} /$ $\mathrm{mL}$ and the two-fold serial dilutions of the purified $\mathrm{mAb}$ ascites fluids from $0.3125 \mu \mathrm{g} / \mathrm{mL}$ to $1.25 \mu \mathrm{g} / \mathrm{mL}$ were tested respectively. The optimal parameters were determined by the highest PI value and then used in the following validation assays. Subsequently, a receiveroperating characteristic (ROC) curve analysis was carried out to determine the cut-off points and assess the discriminating performance of the established cELISA assay for $\mathrm{H} 7$ antibody detection with $\mathrm{HI}$ assay as the gold standard test.

\section{Specificity and sensitivity for $\mathrm{H} 7$ antibody detection}

A panel of standard monospecific antisera produced against other non-H7 AIVs, NDV, IBV, IBDV and ALVJ were used to assess the specificity of the cELISA assay. In order to test the sensitivity of established cELISA assay to detect $\mathrm{H} 7$ antibodies, two-fold serial dilutions of chicken, duck and peacock hyperimmune sera against H7 subtype starting from one-quarter were subjected to the cELISA by comparison to homologous HI assay. The chicken hyperimmune sera used for sensitivity test were selected from both experimental standard sera and field sera samples confirmed by HI assay; the duck and peacock hyperimmune sera were selected from field sera samples confirmed by $\mathrm{HI}$ assay.

\section{Repeatability test}

In order to analyze the reproducibility and reliability of the cELISA immunoassay, the same positive and negative chicken, duck and peacock sera verified by $\mathrm{HI}$ assay were tested by the same batch and different batches of constructed ELISA plates. The chicken sera were selected from prepared experimental standard sera and field sera samples verified by HI assay; the duck and peacock sera were selected from clinical sera samples verified by $\mathrm{HI}$ assay. The mean PI values, standard deviation (SD) and coefficient of variation (CV) were calculated to measure the uniformity within and between batches of the cELISA assay. The CV is defined as the ratio of the $\mathrm{SD}$ to the mean.

\section{Clinical applicability study}

For evaluation of clinical application performance, a total of 400 field serum samples from chicken, duck and peacock were tested for the presence of $\mathrm{H} 7$ antibody by the cELISA assay and homologous HI test in parallel. Subsequently, The diagnostic sensitivity, specificity and accuracy of the cELISA assay compared to HI test were calculated by the following formulas: Sensitivity $=$ True positive/(True positive+False negative) $\times 100 \%$, Specificity $=$ True negative $/($ False positive + True negative $) \times$ $100 \%$ and Accuracy $=($ True positive + True negative $) /$ total number of serum samples tested $\times 100 \%$.

\section{HI assay}

The HI assay was performed in microtiter plates as described previously with $1 \%$ chicken red blood cells and 8 hemagglutinin units (8 HAU) of virus [19]. One HA unit is represented by the highest dilution of virus giving complete hemagglutination. The $\mathrm{HI}$ titer is expressed as the highest dilution of serum resulting in complete inhibition of $8 \mathrm{HAU}$ of virus. The HI titer is regarded as being positive if there is inhibition at a serum dilution of $1 / 16$ or more against $8 \mathrm{HAU}$ of virus. In order to validate the results of the established cELISA for $\mathrm{H} 7$ antibody detection, all sera were tested by both $\mathrm{HI}$ assay and the cELISA for $\mathrm{H} 7$ antibody detection in parallel.

\section{Statistical analysis}

The area under ROC curves (AUC) and optimal cut-off points of the cELISA assay were determined with HI assay as the gold standard method by using Graphpad Prism Software Version 5.0. The AUC value describes an overall summary statistic of diagnostic accuracy which can distinguish between non-informative (AUC = $0.5)$, less accurate $(0.5<\mathrm{AUC} \leq 0.7)$, moderately accurate $(0.7<\mathrm{AUC} \leq 0.9)$, highly accurate $(0.9<\mathrm{AUC}<1)$ and perfect tests $(A U C=1)$. The optimal cutoff points were ascertained as the serum antibody titers corresponding to the PI values at which both specificity and sensitivity of the assay were maximized.

The correlation between the cELISA and HI test was interpreted by the Pearson correlation coefficient ( $\mathrm{r}$ ) 
which varies between -1 and +1 . Zero implies there is no correlation while 1 implies a perfect correlation. The strength of the correlation rises from 0 to +1 , and from 0 to -1 . The $p$-value manifests the probability that the strength of correlation may occur by chance.

The strength of agreement between the cELISA and homologous HI test for field serum sample testing was assessed by Cohen's $\kappa$ value through IBM SPSS Statistics 23. The $\mathrm{K}$ values are interpreted in line with the criteria given by Landis and Koch [20]. $(\kappa \leq 0.00$ was designated as poor agreement, $0.00<\mathrm{K} \leq 0.20$ slight agreement, $0.21<\kappa \leq 0.40$ fair agreement, $0.41<\kappa \leq 0.60$ moderate agreement, $0.61<\kappa \leq 0.80$ substantial agreement, and $0.81<\kappa<1.00$ almost perfect agreement.)

\section{Results}

\section{Development of the H7 cELISA}

The $\mathrm{mAb} 2 \mathrm{~F} 8$ is an IgG2a isotype with kappa light chains. The concentration for purified ascites of $2 \mathrm{~F} 8$ was $2 \mathrm{mg} / \mathrm{mL}$. The purified ascites of $\mathrm{mAb} 2 \mathrm{~F} 8$ served as the competitive $\mathrm{mAb}$ for assay establishment.

By way of checkerboard titration analysis, the optimal concentration of coated antigen was fixed on $4 \mu \mathrm{g} / \mathrm{mL}$ and the optimal concentration of 2F8 competitive mAb was fixed on $0.625 \mu \mathrm{g} / \mathrm{mL}$ (Fig. 2). The $1 / 5$ dilution of test sera was selected considering the highest PI values and widest window for detection of positive and negative serum samples (Fig. 2). The most suitable dilution ratio for horseradish peroxidase-labeled goat anti-mouse IgG conjugate was 1:5000. These optimized parameters were applied for further validation of the cELISA.

Comparison was conducted to evaluate the effectiveness for $\mathrm{H} 7$ antibody detection of these two reaction patterns, including simultaneous incubation and stepby-step incubation of test sera and competitive mAb. It was indicated that the cELISA using simultaneous incubation of test sera and competitive mAb showed best diagnostic performance and reduced assay duration and was then selected for further validation.
A panel of 435 chicken, duck and peacock experimental and field sera confirmed as positive or negative by HI assay were used for construction of ROC curves. Positive sera included samples which cover the range of antibody titers from high to low levels. The AUC values suggested that the cELISA assay for $\mathrm{H} 7$ antibody detection was highly accurate (AUC = 1, 0.9976 and 0.9973 for differentiation of chicken, duck and peacock positive and negative sera respectively). ROC analysis for the cELISA was performed over a range of possible cut-off points (Table 2). The optimal cut-off values to define positive and negative test outcomes were determined to be 30.11, 26.85 and $45.66 \%$ for chicken, duck and peacock test sera respectively, representing the optimal balance of all $100 \%$ diagnostic specificity and sensitivity for chicken sera, $100 \%$ diagnostic specificity and $98.10 \%$ sensitivity for duck sera, $100 \%$ diagnostic specificity and $99 \%$ sensitivity for peacock sera (Fig. 3).

\section{Specificity and sensitivity of the H7 CELISA}

As was shown in Fig. 4, the $\mathrm{H} 7$ monospecific standard chicken serum gave over $80 \%$ inhibition percentage while standard sera containing antibodies directed against other subtypes and other avian viruses gave inhibition percentage from -14.72 to $20.27 \%$, significantly lower than the detection threshold. The H7 cELISA assay could specifically detect $\mathrm{H} 7$ antibodies against $\mathrm{H} 7$ AIV in positive sera, and had no serological crossreactivity with sera against other non-H7 AIVs, NDV, IBV, IBDV and ALV-J.

In this study, a pool of two-fold serially diluted strong positive sera from chicken, duck and peacock were subjected to both the cELISA and homologous HI assay for assessment of analytical sensitivity for the cELISA immunoassay and their correlation. As illustrated in Fig. 5, a strong correlation was observed between PI values and $\mathrm{HI}$ titers on a logarithmic scale with a very high statistical significance $(p<0.0001)$ according to $\mathrm{r}$ values reported to be 0.9883, 0.9918 and 0.9413 for chicken, duck and peacock test sera, respectively (95\% confidence interval). In the
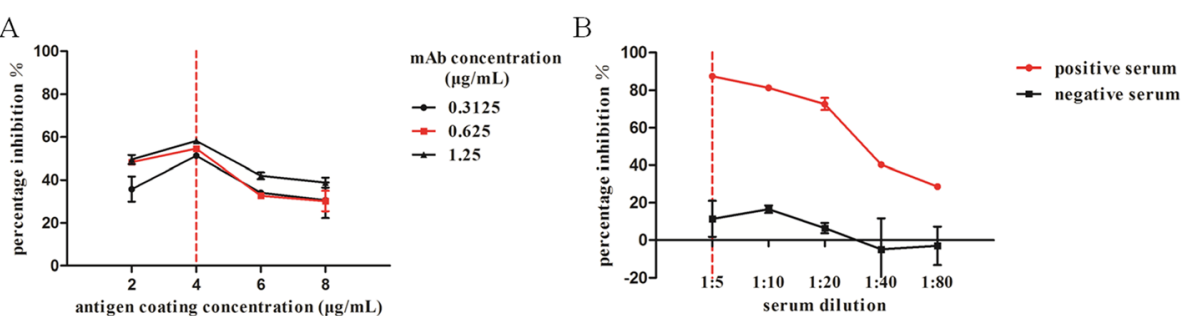

Fig. 2 Optimization of test parameters for the CELISA immunoassay. a The coating antigen concentrations of 2, 4, 6 and $8 \mu \mathrm{g} / \mathrm{mL}$ and 2-fold serial dilutions of the 2 F8 purified ascites varied from 0.3125 to $1.25 \mu \mathrm{g} / \mathrm{mL}$ were tested respectively by checkerboard titration. b After the optimal antigen and competitive antibody concentrations were determined, the optimal dilution ratio for test sera was determined by 2-fold serial dilution from 1:5 to 1:80. The combination that gave the highest PI values was determined to be $4 \mu \mathrm{g} / \mathrm{mL}$ antigen, $0.625 \mu \mathrm{g} / \mathrm{mL} \mathrm{mAb}$ and 1:5 dilution ratio of test serum. The red vertical dotted lines indicate the optimal working condition 
Table 2 Evaluation of the cELISA immunoassay with selected cut-off values

\begin{tabular}{llll}
\hline Species & Cut-off values (\%) & Sensitivity (\%) & Specificity (\%) \\
\hline Chicken & 24.77 & 100.0 & 99.00 \\
& 30.11 & 100.0 & 100.0 \\
& 36.50 & 98.00 & 100.0 \\
& 42.25 & 96.00 & 100.0 \\
& 22.39 & 98.10 & 97.50 \\
& 26.85 & 98.10 & 100.0 \\
& 32.63 & 97.14 & 100.0 \\
& 39.50 & 96.19 & 100.0 \\
& 36.88 & 99.00 & 97.50 \\
& 45.66 & 99.00 & 100.0 \\
& 55.21 & 98.00 & 100.0 \\
& 58.67 & 97.00 & 100.0 \\
\hline
\end{tabular}

light of determined optimal cut-off values to discriminate between positive and negative sera, the analytical sensitivity for the cELISA was reported down to $2^{0}, 2^{1}$ and $2^{-1} \mathrm{HI}$ titer for chicken, duck and peacock test sera.

\section{Stability of the H7 cELISA immunoassay}

The evaluation of the reproducibility was carried out within and between runs for analysis of chicken, duck and peacock sera confirmed by $\mathrm{HI}$ assay respectively. Through statistical analysis, the intra-batch CVs of the 15 tested sera ranged from 0.19 to $6.17 \%$, whereas the inter-batch CVs ranged from 2.94 to $15.15 \%$ (Table 3). These results demonstrated that the cELISA immunoassay were reproducible with low and acceptable variation.

\section{Diagnostic performance in field samples}

To test the applicability in clinical use, a total of 400 field serum specimens from chicken, duck and peacocks were screened for the existence of $\mathrm{H} 7$ antibodies by using cELISA and HI assay (Table 4). It was shown that a total of 245 out of the 400 samples tested positive, and 155 samples tested negative according to the HI assay while a total of 242 positive samples and 158 negative samples were detected by the cELISA. Overall, the positive rates for $\mathrm{HI}$ assay and the cELISA were calculated as 61.3 and $60.5 \%$ respectively. For chicken test sera, the cELISA was found to be $100 \%$ specific and $100 \%$ sensitive relative to $\mathrm{HI}$ assay; for duck test sera, the cELISA was found to be $100 \%$ specific and $98.1 \%$ sensitive relative to $\mathrm{HI}$ assay; for peacock test sera, the cELISA was found to be $100 \%$ specific and $99 \%$ sensitive relative to $\mathrm{HI}$ assay. The diagnostic accuracy of the cELISA relative to $\mathrm{HI}$ assay for chicken, duck and peacock test sera were reported to be 100, 98.6 and $99.3 \%$ respectively. The agreement between the cELISA and HI assay was assessed by Cohen's $\mathrm{K}$ analysis. According to the reported $\kappa$ values $(\kappa=1.000$ for chicken sera; $\kappa=0.966$ for duck sera; $\kappa=0.983$ for peacock sera), an almost perfect agreement was observed between the two methods for the three species.

\section{Discussion}

The continual prevalence of H7 AIV in poultry constitutes an enormous challenge towards the poultry industry and human public health. Effective prevention and control of $\mathrm{H} 7$ outbreaks require active global serological surveillance in poultry. For early detection and control of subclinical H7 infection, extensive serological surveillance programs in poultry have been carried out by the European Union [21]. Moreover, full-scale vaccination
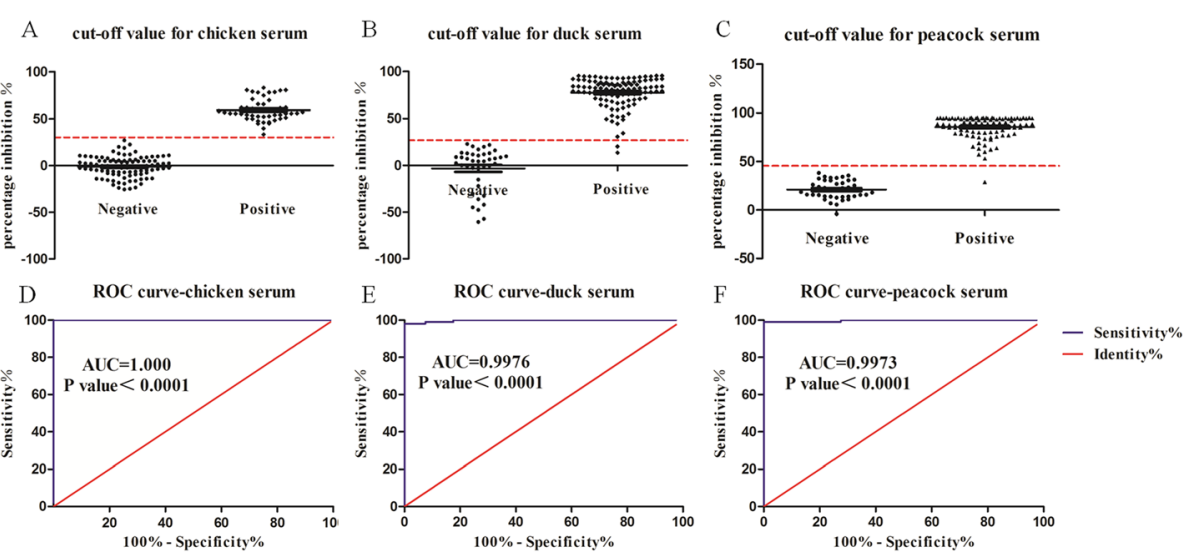

Fig. 3 Interactive dot diagram for detection of $\mathrm{H} 7$ antibodies in chicken (a), duck (b) and peacock (c) sera and ROC curves for detection of H7 antibodies in chicken $(\mathbf{d})$, duck (e) and peacock (f) sera used to set the cut-off values for the cELISA immunoassay. Each dot represents one serum sample. The horizontal dotted lines indicate the optimal cut off levels with the best sensitivity and specificity. AUC represents area under the curve 


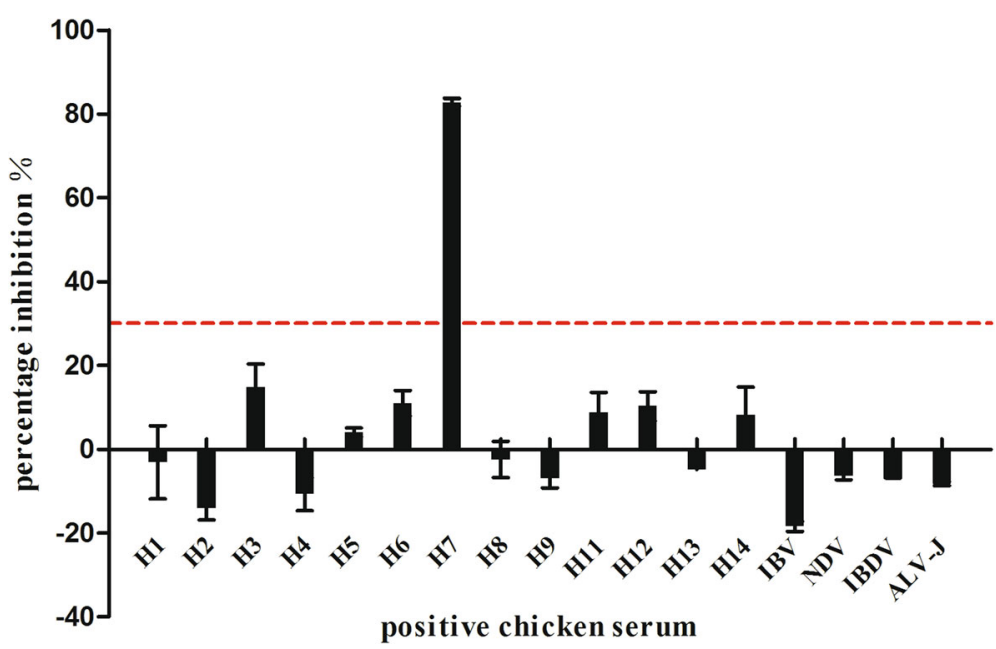

Fig. 4 The cross-reactivity of the competitive ELLISA immunoassay with standard chicken positive antisera against different HA subtypes of AIV and other avian viruses. The horizontal dotted lines indicate the cut-off value of $30.11 \%$ for chicken sera. The arithmetic mean of PI values for standard positive sera against AIV of $\mathrm{H} 1-\mathrm{H} 9$ and $\mathrm{H} 11-\mathrm{H} 14$ subtypes, NDV, IBV, IBDV and ALV-J were much lower than $30.11 \%$ except for the H7 positive serum

campaigns have been enforced throughout China to prevent $\mathrm{H} 7$ outbreaks in poultry since 2017 . With the increase of sampling for sero-surveillance and vaccination efficacy studies, it is urgent to develop novel rapid $\mathrm{H} 7$ subtype-specific serological assay for antibody screening. Currently, the cELISA techniques contribute to the rapid high-throughput detection of subtype-specific AIV antibodies in poultry flocks. This study aimed to develop and validate a cELISA immunoassay for $\mathrm{H} 7$ antibody early detection in sera from different avian species after viral infection and vaccination.

In this study, the effect of purified $\mathrm{H} 7$ whole virus particles or histidine-tagged recombinant $\mathrm{H} 7-\mathrm{HA} 1$ protein expressed in a prokaryotic system as the coating antigen was investigated. And the finding was that the same standard positive antisera against $\mathrm{H} 7$ subtype exhibited a higher PI value with purified $\mathrm{H} 7$ whole virion as the coating antigen in comparison to recombinant H7-HA1 protein. Possible explanation for this disparity was that the denatured recombinant H7-HA1 protein differed from the native structure of the corresponding HA1 domain of H7 AIV.

The advantages of using mAbs for detecting AIV include high specificity, sensitivity and unlimited provision of a standardized reagent. mAbs against the HA protein of AIV served as a useful tool to distinguish its subtypes in previous studies [22-24]. In the present paper, the cELISA immunoassay for $\mathrm{H} 7$ antibody detection was developed using an anti-H7-HA1 mAb targeting the epitope located in the depression under antigenic site $\mathrm{E}$ of H7-HA1 subunit [17]. Through alignment of epitope sequences, the epitope recognized by mAb $2 \mathrm{~F} 8$ was found to be highly conserved in $\mathrm{H} 7$ strains of Eurasian lineage while not found in any other subtypes of AIV [17]. At present, the commercial $\mathrm{H} 5 / \mathrm{H} 7$ trivalent vaccine used in China was developed by using inactivated whole virus containing major HA antigen, thus the vaccination induced the same type of antibodies in poultry as those infected naturally. Given that the established cELISA assay detected specific antibodies against the HA protein of H7 AIV, it will be useful for sero-surveillance investigation but not suitable for outbreak diagnosis.

Conventionally, the Gaussian distribution approach is commonly used to identify cut-off values for diagnostic tests. For this approach, a cut-off value is defined as the mean plus two standard deviations (2SD) of the negative reference samples, which ensured a diagnostic specificity of $97.5 \%$ without considering the diagnostic sensitivity [25]. In this study, we determined the baseline cut-off values by use of ROC curves analysis which enabled a combined measure of diagnostic sensitivity and specificity. For serological subtyping of the avian influenza virus, $\mathrm{HI}$ test is regarded as the gold standard in routine diagnostic practice recommended by OIE. So the ROC curve analysis was built on the classification results of sera by HI assay. For ROC analysis, the AUC determines the inherent predictive ability of the test to discriminate between positive and negative sera. In this study, the developed cELISA assay turned out to be significantly reliable with the threshold PI values of 30.11, 26.85 and $45.66 \%$ for chicken, duck and peacock test sera (AUC = 1, 0.9976 and $0.9973, p$ value $<0.0001$, satisfactory sensitivity and specificity were achieved). It was shown that the determined cut-off value for peacock sera was higher than that for chicken and duck sera. Such variation among different avian species has been already reported 


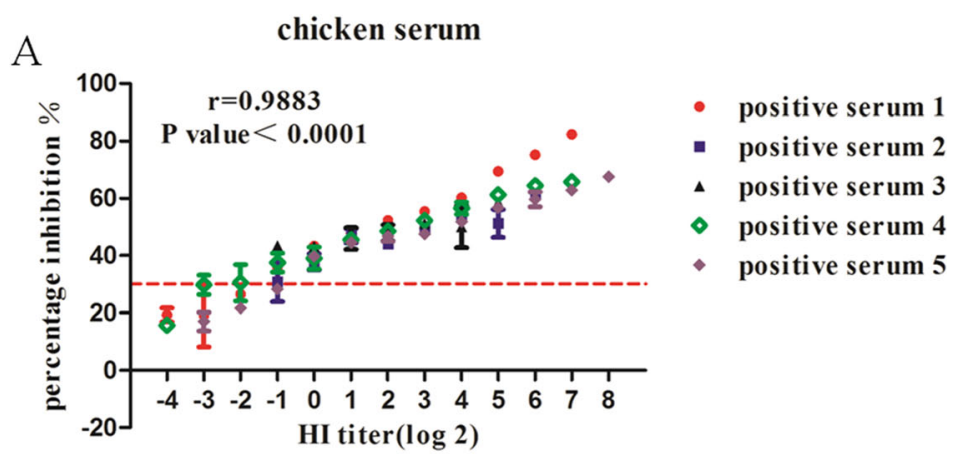

$\mathrm{B}$

Duck serum

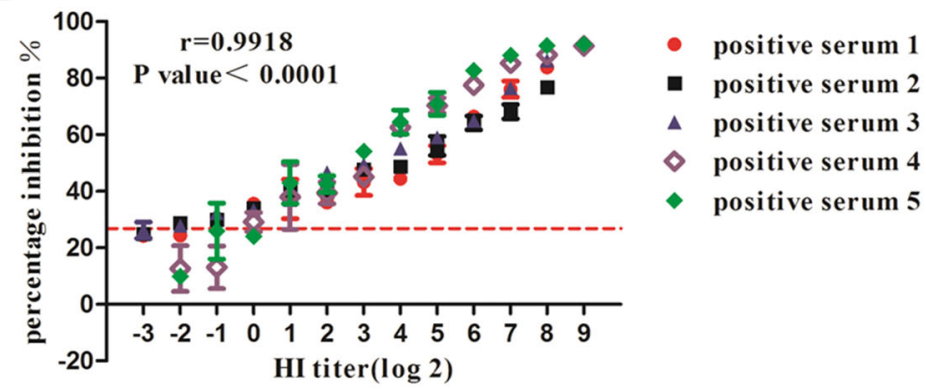

$\mathrm{C}$

Peacock serum

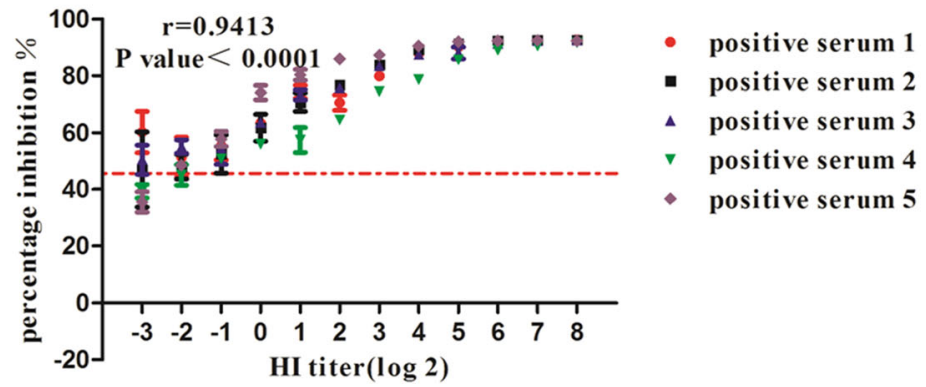

Fig. 5 The sensitivity of the H7 CELISA assay for the detection of $\mathrm{H7}$ antibody and the correlation between H7 cELISA and HI assay. A panel of H7 strong positive chicken (a), duck (b) and peacock (c) sera were twofold diluted and subjected to the cELISA and HI assay for H7 antibody detection. The horizontal dotted lines indicate the cut off value and $r$ represents Pearson correlation coefficient

in the literature [26]. The different reactivity of sera across distinct species with the same coating antigen can be explained by the various serum compositions and immune responses in a species-dependent manner.

The cELISA immunoassay format is expected to test sera from diverse hosts without changing any test reagents. To verify the capability of the developed cELISA assay to analyze sera from different hosts, field specimens from a variety of avian species were used for $\mathrm{H} 7$ antibody detection, including chicken, duck and peacock. It was shown that the cELISA assay yielded diagnostic results in a high accordance rate with the gold standard $\mathrm{HI}$ assay for $\mathrm{H} 7$ antibody detection in accordance with the determined cut-off values. Based on this study, the constructed multi-species cELISA assay is of practical use for evaluating vaccination effectiveness of zoo birds other than domestic poultry and waterfowl. The cELISA assay will be further evaluated and applied in other avian species.

The newly developed cELISA immunoassay has been proved to be more effective in terms of sensitivity, efficiency and biosafety. As demonstrated by the results that detection limits of the $\mathrm{H} 7$ antibodies for chicken, duck and peacock test sera reached $2^{0}, 2^{1}$ and $2^{-1} \mathrm{HI}$ titer respectively, the cELISA was superior in analytical sensitivity when compared to $\mathrm{HI}$ assay by which a serum with $2^{4}$ or more than $2^{4} \mathrm{HI}$ titers was diagnosed as being positive. Furthermore, the analytical sensitivity for chicken sera was improved by 16 -fold using this novel immunoassay as confirmed by comparison of the previously developed cELISA assay [27]. Although the HI assay is routinely used for subtyping in AIV serologic 
Table 3 Intra and Inter-assay repeatability of the cELISA immunoassay

\begin{tabular}{|c|c|c|c|c|c|c|c|c|}
\hline \multirow[t]{3}{*}{ Species } & \multirow[t]{3}{*}{ Serum samples } & \multirow{3}{*}{$\begin{array}{l}\mathrm{HI} \\
\text { titer }\end{array}$} & \multicolumn{6}{|c|}{ Inhibition percentage } \\
\hline & & & \multicolumn{3}{|l|}{ Intra-assay } & \multicolumn{3}{|l|}{ Inter-assay } \\
\hline & & & Mean (\%) & SD & CV (\%) & Mean (\%) & SD & CV (\%) \\
\hline \multirow[t]{5}{*}{ Chicken } & Positive serum 1 & $2^{6}$ & 77.30 & 0.014 & 1.92 & 76.34 & 0.052 & 6.91 \\
\hline & Positive serum 2 & $2^{8}$ & 78.34 & 0.003 & 0.35 & 70.07 & 0.095 & 13.62 \\
\hline & Positive serum 3 & $2^{9}$ & 81.50 & 0.005 & 0.67 & 85.76 & 0.049 & 5.74 \\
\hline & Negative serum 1 & - & 29.01 & 0.002 & 0.82 & 29.76 & 0.013 & 4.43 \\
\hline & Negative serum 2 & - & 14.89 & 0.009 & 6.17 & 19.50 & 0.027 & 14.04 \\
\hline \multirow[t]{5}{*}{ Duck } & Positive serum 1 & $2^{10}$ & 89.69 & 0.011 & 1.22 & 84.20 & 0.064 & 7.56 \\
\hline & Positive serum 2 & $2^{10}$ & 88.75 & 0.007 & 0.81 & 81.50 & 0.091 & 11.12 \\
\hline & Positive serum 3 & $2^{10}$ & 86.72 & 0.017 & 1.91 & 81.73 & 0.059 & 7.18 \\
\hline & Negative serum 1 & - & 13.00 & 0.002 & 1.57 & 13.21 & 0.004 & 2.94 \\
\hline & Negative serum 2 & - & 22.39 & 0.007 & 3.27 & 20.61 & 0.031 & 15.15 \\
\hline \multirow[t]{5}{*}{ Peacock } & Positive serum 1 & $2^{9}$ & 85.46 & 0.014 & 1.69 & 80.66 & 0.056 & 6.96 \\
\hline & Positive serum 2 & $2^{9}$ & 85.07 & 0.024 & 2.85 & 89.63 & 0.054 & 6.07 \\
\hline & Positive serum 3 & $2^{9}$ & 93.99 & 0.002 & 0.19 & 90.13 & 0.045 & 4.95 \\
\hline & Negative serum 1 & - & 15.94 & 0.001 & 0.20 & 15.66 & 0.014 & 8.74 \\
\hline & Negative serum 2 & - & 11.12 & 0.002 & 1.66 & 11.87 & 0.013 & 11.04 \\
\hline
\end{tabular}

surveillance, it is laborious and time-consuming for red blood cells preparation, antigen cultures, serum samples serial dilutions and manual reading of results. The pansubtype cELISA assay can serve as a multi-species AIV serological screening tool yet $\mathrm{HI}$ assay is required for further subtyping [28]. In this study, the developed cELISA assay is easy to automate for large-scale monitoring of $\mathrm{H} 7$ subtype-specific antibody in sera from various avian species for its simplicity of operation, instrumental reading and easy interpretation of the results. It is worth mentioning that the entire test only takes about $95 \mathrm{~min}$, which is several times faster than the $\mathrm{HI}$ test when processing a large number of samples. In addition, the established cELISA assay had a biosafety advantage in comparison to $\mathrm{HI}$ assay. The established
cELISA assay is easy to be applied in laboratories with low-level biosafety regulations, while $\mathrm{HI}$ assay can only be operated in the high-level biosafety laboratories when handling live virus.

Overall, an excellent correlation was observed between the HI test and the novel cELISA immunoassay for the detection of $\mathrm{H} 7$ antibody. For the tested panels of field serum samples, diagnostic results for the cELISA assay were highly consistent with homologous $\mathrm{HI}$ assay along with 100, 98.6 and $99.3 \%$ diagnostic accuracy for chicken, duck and peacock sera. An excellent agreement was observed between HI assay and the novel cELISA immunoassay for clinical diagnostic performance by Cohen's $\kappa$ analysis. Considering these advantages, the cELISA assay introduced in this study turned out to be a

Table 4 Comparison study between the CELISA immunoassay and HI assay for the detection of H7 antibody in chicken, duck and peacock field serum samples

\begin{tabular}{|c|c|c|c|c|c|c|}
\hline \multirow[t]{2}{*}{ Target } & \multicolumn{2}{|c|}{ Chicken serum } & \multicolumn{2}{|c|}{ Duck serum } & \multicolumn{2}{|c|}{ Peacock serum } \\
\hline & H7 cELISA & HI test & H7 cELISA & HI test & H7 cELISA & HI test \\
\hline Positive & 40 & 40 & 103 & 105 & 99 & 100 \\
\hline Negative & 75 & 75 & 42 & 40 & 41 & 40 \\
\hline Positive rates & $34.8 \%$ & $34.8 \%$ & $71.0 \%$ & $72.4 \%$ & $70.7 \%$ & $71.4 \%$ \\
\hline Sensitivity ${ }^{a}(T P /(T P+F N))$ & $100 \%$ & & $98.1 \%$ & & $99 \%$ & \\
\hline Specificity ${ }^{b}(T N /(T N+F P))$ & $100 \%$ & & $100 \%$ & & $100 \%$ & \\
\hline Accuracy ${ }^{c}((\mathrm{TP}+\mathrm{TN}) /$ Total $)$ & $100 \%$ & & $98.6 \%$ & & $99.3 \%$ & \\
\hline
\end{tabular}

${ }^{\mathrm{a}} T P$ true positive, $F N$ false negative; sensitivity $=(\mathrm{TP} /(\mathrm{TP}+\mathrm{FN})) \times 100 \%$

b $T N$ true negative, $F P$ false positive; specificity $=(T N /(T N+F P)) \times 100 \%$

c Total, total number of serum samples; Accuracy $=((\mathrm{TP}+\mathrm{TN}) /$ Total $) \times 100 \%$ 
valid and efficient tool for titration of $\mathrm{H} 7$ antibodies in large amounts of chicken, duck or peacock sera.

Both H5 and H7 subtype AIV should be reported to OIE for their high risk of becoming HPAIV after transmission to domestic poultry. Furthermore, their devastating impact on the poultry industry and zoonotic potential underscore the great need to develop rapid and effective serological screening tools for early detection and control of subclinical H5 and H7 infection. Therefore, further studies should be performed to develop cELISA assays for simultaneous detection of antibodies against both $\mathrm{H} 5$ and $\mathrm{H} 7$ subtype AIV.

\section{Conclusions}

Considering the high agreement with $\mathrm{HI}$ assay, the cELISA assay based on anti-H7-HA1 mAb and wholevirus virion described in this paper proved to be an attractive choice for evaluating the specific antibody levels against $\mathrm{H} 7$ subtype in serum samples from different avian species of interest. It was amenable to rapid and high throughput screening for $\mathrm{H} 7$ antibody with brilliant specificity, sensitivity and reproducibility. In the future, it offers a promising approach for massive epidemiological screening and sero-surveillance of antibody response against $\mathrm{H7}$ subtype.

\section{Abbreviations}

AGID: Agar gel immunodiffusion; AIV: Avian influenza virus; ALV-J: Avian leukosis virus-J subgroup; AUC: The area under ROC curves; CELISA: Competitive enzyme-linked immunosorbent assay: CV: Coefficient of variation; ELISA: Enzyme-linked immunosorbent assay; HA: Hemagglutinin; HAU: Hemagglutinin units; HI: Hemagglutination inhibition; HPAIV: Highly pathogenic avian influenza virus; IBDV: Infectious bursal disease virus; IBV: Avian infectious bronchitis virus; LPAIV: Low pathogenicity avian influenza virus; mAb: Monoclonal antibody; NA: Neuraminidase; NDV: Newcastle disease virus; VN: Virus neutralization; $\mathrm{OD}_{450}$ : Optical density at 450 nm; PBS: Phosphate buffered saline; PBST: PBS buffer containing 0.05\% Tween-20; PI: Percentage of inhibition; ROC: Receiver-operating characteristic; SD: Standard deviation; SPF: Specific-pathogen-free;

TMB: Tetramethylbenzidine

\section{Acknowledgements}

Not applicable.

\section{Authors' contributions}

LPY and YL carefully conceived and designed the study. YL performed the experiments and analyzed the results. YL, HLY, ML and WKC collected the clinical samples. YL and LPY wrote the manuscript. LPY, SQS and JC analyzed the data and revised the manuscript. All authors reviewed the results and approved the final version of the manuscript.

\section{Funding}

The experimental standard sera preparation and clinical serum samples collection were supported by the Forestry Science and Technology Innovation and Promotion Project of Jiangsu Province (LYKJ[2018]22) and the National Key Research and Development Program of China (2016YFD0501600). The experiments implementation and data analysis and interpretation were supported by the Natural Science Foundation of Jiangsu Province (BK20181321). The writing of the manuscript was supported by the China Agriculture Research System (CARS-40-K13) and Priority Academic Program Development of Jiangsu Higher Education Institutions.

\section{Availability of data and materials}

The datasets used and/or analyzed during the current study are available from the corresponding author on reasonable request.

\section{Ethics approval and consent to participate}

All animals used in the study were treated in accordance with the guidelines for the care and use of laboratory animals of the Ministry of Health, China. The experimental protocols used in the animal studies were censored and approved by the Institutional Animal Care and Use Committee of Nanjing Agricultural University (approved NO. SYXK (Su) 2017-0007). Written informed consent to use 400 clinical serum samples, which were collected from poultry farms and Nanjing Hongshan Forest Zoo, were obtained from the owners of the animals. All efforts were made to minimize animal suffering during sample collection.

\section{Consent for publication}

Not applicable.

\section{Competing interests}

The authors declare that they have no competing interests.

\section{Author details}

${ }^{1} \mathrm{MOE}$ Joint International Research Laboratory of Animal Health and Food Safety, Jiangsu Engineering Laboratory of Animal Immunology, Jiangsu Detection Center of Terrestrial Wildlife Disease, Institute of Immunology and College of Veterinary Medicine, Nanjing Agricultural University, Nanjing, Jiangsu 210095, People's Republic of China. ${ }^{2}$ Institute of Veterinary Immunology \& Engineering, Jiangsu Academy of Agricultural Sciences, Nanjing, Jiangsu 210014, People's Republic of China. ${ }^{3}$ Nanjing Hongshan Forest Zoo, Nanjing, Jiangsu 210000, People's Republic of China.

Received: 22 June 2020 Accepted: 19 January 2021

Published online: 02 February 2021

\section{References}

1. Kaye D, Pringle CR. Avian influenza viruses and their implication for human health. Clin Infect Dis. 2005:40(1):108-12.

2. Capua I, Alexander DJ. Human health implications of avian influenza viruses and paramyxoviruses. Eur J Clin Microbiol Infect Dis. 2004;23(1):1-6.

3. Webster RG, Govorkova EA. Continuing challenges in influenza. Ann N Y Acad Sci. 2014;1323:115-39.

4. Lycett SJ, Duchatel F, Digard P. A brief history of bird flu. Philos Trans R Soc Lond Ser B Biol Sci. 2019;374(1775):20180257.

5. Sutton TC. The pandemic threat of emerging $\mathrm{H} 5$ and $\mathrm{H} 7$ avian influenza viruses. Viruses. 2018;10(9):461.

6. Naguib MM, Verhagen JH, Mostafa A, Wille M, Li R, Graaf A, Jarhult JD, Ellstrom P, Zohari S, Lundkvist A, et al. Global patterns of avian influenza A (H7): virus evolution and zoonotic threats. FEMS Microbiol Rev. 2019:43(6): 608-21

7. Abdelwhab EM, Veits J, Mettenleiter TC. Prevalence and control of $\mathrm{H7}$ avian influenza viruses in birds and humans. Epidemiol Infect. 2014;142(5):896920.

8. Capua I, Alexander DJ. Avian influenza: recent developments. Avian Pathol. 2004;33(4):393-404.

9. Alexander DJ, Brown IH. History of highly pathogenic avian influenza. Rev Sci Tech. 2009;28(1):19-38.

10. Belser JA, Bridges CB, Katz JM, Tumpey TM. Past, present, and possible future human infection with influenza virus A subtype H7. Emerg Infect Dis. 2009:15(6):859-65.

11. Poovorawan Y, Pyungporn S, Prachayangprecha S, Makkoch J. Global alert to avian influenza virus infection: from H5N1 to H7N9. Pathog Glob Health. 2013;107(5):217-23.

12. Charlton B, Crossley B, Hietala S. Conventional and future diagnostics for avian influenza. Comp Immunol Microbiol Infect Dis. 2009:32(4):341-50.

13. Katz JM, Hancock K, Xu X. Serologic assays for influenza surveillance, diagnosis and vaccine evaluation. Expert Rev Anti-Infect Ther. 2011;9(6):669_ 83.

14. Okamatsu M, Hiono T, Kida H, Sakoda Y. Recent developments in the diagnosis of avian influenza. Vet J. 2016;215:82-6.

15. Spackman E, Killian ML. Detection of influenza $A$ antibodies in avian samples by ELISA. Methods Mol Biol. 2020;2123:177-93. 
16. Wiley DC, Skehel JJ. The structure and function of the hemagglutinin membrane glycoprotein of influenza virus. Annu Rev Biochem. 1987;56:36594.

17. Yao L, Chen Y, Wang X, Bi Z, Xiao Q, Lei J, Yan Y, Zhou J, Yan L. Identification of antigenic epitopes in the haemagglutinin protein of $\mathrm{H} 7$ avian influenza virus. Avian Pathol. 2020;49(1):62-73.

18. Xiao Q, Bi Z, Yao L, Lei J, Yan Y, Zhou J, Yan L. Novel protein microarray for the detection of avian influenza virus antibodies and simultaneous distinction of antibodies against H5 and H7 subtypes. Avian Pathol. 2019; 48(6):528-36.

19. Pedersen JC. Hemagglutination-inhibition test for avian influenza virus subtype identification and the detection and quantitation of serum antibodies to the avian influenza virus. Methods Mol Biol. 2008:436:53-66.

20. Landis JR, Koch GG. The measurement of observer agreement for categorical data. Biometrics. 1977;33(1):159-74.

21. Hillman AE, Smith RP, Batey N, Verheyen KL, Pittman M, Brown IH, Breed AC Serological surveillance reveals patterns of exposure to $\mathrm{H} 5$ and $\mathrm{H} 7$ influenza A viruses in European poultry. Transbound Emerg Dis. 2020;67(2):592-603.

22. Yang F, Xiao Y, Chen B, Wang L, Liu F, Yao H, Wu N, Wu H. Development of a colloidal gold-based immunochromatographic strip test using two monoclonal antibodies to detect H7N9 avian influenza virus. Virus Genes. 2020;56(3):396-400.

23. Wang H, Zhou J, Wang D, Huang B, Tan W. Development and optimized pairing of mouse monoclonal antibodies for detecting hemagglutinin in novel H7 subtype influenza viruses. Sci China Life Sci. 2020;63(2):279-89.

24. Moreno A, Lelli D, Brocchi E, Sozzi E, Vinco $\amalg$, Grilli G, Cordioli P. Monoclonal antibody-based ELISA for detection of antibodies against H5 avian influenza viruses. J Virol Methods. 2013;187(2):424-30.

25. Greiner M, Pfeiffer D, Smith RD. Principles and practical application of the receiver-operating characteristic analysis for diagnostic tests. Prev Vet Med. 2000;45(1-2):23-41.

26. Henriques AM, Fagulha T, Barros SC, Ramos F, Duarte M, Luis T, Fevereiro M. Development and validation of a blocking ELISA test for the detection of avian influenza antibodies in poultry species. J Virol Methods. 2016;236:4753.

27. Dong J, Fan J, Wang Y, Zhang Q, Yang Y, Jia Y, Ming F, Zhang X, Yao R, Li S, et al. Development and evaluation of a C-ELISA for rapid detection of antibody to AIV- H7. Anal Biochem. 2019;572:52-7.

28. Starick E, Werner O, Schirrmeier H, Kollner B, Riebe R, Mundt E.

Establishment of a competitive ELISA (cELISA) system for the detection of influenza A virus nucleoprotein antibodies and its application to field sera from different species. J Vet Med B Infect Dis Vet Public Health. 2006;53(8): $370-5$.

\section{Publisher's Note}

Springer Nature remains neutral with regard to jurisdictional claims in published maps and institutional affiliations.

Ready to submit your research? Choose BMC and benefit from:

- fast, convenient online submission

- thorough peer review by experienced researchers in your field

- rapid publication on acceptance

- support for research data, including large and complex data types

- gold Open Access which fosters wider collaboration and increased citations

- maximum visibility for your research: over $100 \mathrm{M}$ website views per year

At $\mathrm{BMC}$, research is always in progress.

Learn more biomedcentral.com/submissions 